\title{
A TEORIA DA RESPONSABILIDADE DE HANS JONAS COMO RESPOSTA ÉTICA AOS PROBLEMAS LEVANTADOS PELA TÉCNICA MODERNA
}

\author{
Hans Jonas' theory of responsibility as an ethical answer to the problems raised by modern \\ technique
}

José Carlos Moreira*

\begin{abstract}
Resumo: $O$ advento da técnica moderna faz emergir novos e desafiadores problemas para o campo da ética e, atrelado a isso, urge a necessidade da formulação de um princípio ético que seja capaz de pensar os avanços da tecnologia. Destarte, nosso objetivo consiste em mostrar em que medida o projeto filosófico de Hans Jonas pode contribuir para o desenvolvimento de uma Teoria da Responsabilidade enquanto imperativo ético que promova a reconciliação entre homem e natureza. Além disso, buscaremos repensar, à luz da teoria da responsabilidade, o paradoxo esperança - medo erguido justamente com o advento da técnica moderna, cujo "braço enormemente prolongado de que hoje dispomos" e do qual emana o nosso poder de interferir no mundo, representa, ao mesmo tempo, ameaça às futuras gerações. Uma vez que a técnica moderna coloca um problema para a ética, Jonas entende que a responsabilidade como uma teoria ética capaz de responder aos problemas colocados pelas modernas tecnologias exige uma fundamentação metafísica. Portanto, podemos compreender que a ética jonasiana é fundada no ser, de modo que a responsabilidade emerge como o novo dever do homem. Finalmente, para exemplificar a noção de responsabilidade como o novo dever do homem, Jonas propõe dois modelos: a responsabilidade dos pais para com os filhos e a responsabilidade do homem público na esfera política.
\end{abstract}

Palavras-chave: Jonas. Tecnologia. Responsabilidade. Ética e Metafísica.

\begin{abstract}
The advent of modern technique has led to new challenging issues in the realm of ethics and, consequently, an urge for the formulation of an ethical principle, capable of taking into account the developments of technology. Our aim consists in showing how Hans Jonas' philosophical project can contribute to the development of a Theory of Responsibility as an ethical imperative which promotes reconciliation between man and nature. In addition, we will attempt to rethink the paradox hope - fear in the light of the theory of responsibility. Such a paradox arose with the advent of modern technique whose "outstretched arm" at our disposal today and from which we draw our power to interfere in the world also represents a serious threat to future generations. Since modern technology has raised ethical issues, Jonas understands that responsibility, as an ethical theory capable of answering the problems created by modern technologies, demands a metaphysical foundation. Therefore, we can fathom that Jonasian ethics is rooted in the being in such a way that responsibility emerges as the new duty of man. Finally, in order to illustrate the notion of responsibility as the new duty of man, Jonas proposes two models: the responsibility of parents for their children, and the responsibility of the political statesmen.
\end{abstract}

Keywords: Jonas. Technology. Responsibility. Ethics and Metaphysics.

* Mestrado em filosofia pela Faculdade Jesuíta de Filosofia e Teologia (FAJE). Contato: aspjosecarlos@hotmail.com

\begin{tabular}{|c|c|c|c|c|c|}
\hline intuitio & $\begin{array}{c}\text { ISSN } \\
1983-4012\end{array}$ & Porto Alegre & Vol.7- $\mathrm{N}^{\mathrm{o}} .2$ & $\begin{array}{c}\text { Novembro } \\
2014\end{array}$ & p. 146-160 \\
\hline
\end{tabular}


A teoria da responsabilidade de Hans Jonas como resposta ética aos problemas levantados pela técnica moderna

\section{Introdução}

O presente artigo pretende, à luz da abordagem filosófica de Hans Jonas (1903-93), mostrar como o desenvolvimento das modernas tecnologias leva ao soerguimento de novos e desafiadores problemas para a dimensão ética. E, atrelado a isso, urge a necessidade de se incluir no agir humano um novo princípio ético que se manifeste concretamente com a mesma proporção e efetividade com qual se manifestam as modernas tecnologias. Destarte, nosso objetivo aqui trata-se de mostrar em que medida o pensamento jonasiano pode lançar luzes sobre o novo modo de agir humano na civilização tecnológica contribuindo, portanto, para o desenvolvimento de uma Teoria da Responsabilidade enquanto imperativo ético capaz de superar a dualidade entre homem e natureza. Buscaremos, à luz da teoria da responsabilidade, repensar o paradoxo esperança - medo erguido com o desenvolvimento da técnica moderna, cujo "braço enormemente prolongado de que hoje dispomos" e do qual emana o nosso poder de interferir no mundo, representa, ao mesmo tempo, ameaça às futuras gerações.

Para matizar a temática que aqui propomos daremos três passos. Primeiro, mostraremos por que para Jonas a técnica moderna é objeto da filosofia e por que o advento da técnica na contemporaneidade coloca um problema para a ética. A partir do resultado da análise destas questões, pretendemos mostrar porque urge a necessidade da formulação de uma teoria da responsabilidade como um novo princípio ético que oriente o homem de hoje no que tange à preservação da integridade da essência humana no futuro. Além da necessária e urgente formulação de um novo princípio ético, o que Jonas chama de responsabilidade para com as gerações vindouras, sublinharemos num segundo momento as bases ontológicas nas quais se apoiam à ética jonasiana. Pois segundo o nosso autor, uma ética capaz de preservar a integridade da essência humana no futuro só pode ser metafisicamente fundamentada. Tal fundamentação, por sua vez, resulta da articulação das categorias de bem, dever e do ser. O dever é fundado no ser, e segue-se daí que a responsabilidade emerge como o novo dever do homem. Finalmente, num terceiro momento, destacaremos a responsabilidade política e a aquela dos pais para com os filhos como modelos nos quais se aplicam a responsabilidade proposta por Jonas.

\section{Da ambivalência da técnica à necessidade de uma ética de reponsabilidade}

O projeto filosófico jonasiano emerge na contemporaneidade como um referencial no âmbito das éticas aplicadas e, mormente nos tempos hodiernos em que a questão ambiental vem animando o debate ético, em razão do domínio técnico da natureza, oriundo da racionalidade moderna. Esta racionalidade se impõe como promessa de liberdade. No entanto, a "profecia de esperança" da racionalidade tecnocientífica aponta para um cenário de risco, onde a espera de realização é revertida

${ }^{1}$ JONAS, H. Técnica, medicina e ética: sobre a prática do princípio responsabilidade. Trad. grupo de trabalho Hans Jonas da ANPOF. (Associação Nacional de pós-graduação em Filosofia), São Paulo: Paulus, 2013, p. 292.

\begin{tabular}{|c|c|c|c|c|c|}
\hline intuitio & $\begin{array}{c}\text { ISSN } \\
1983-4012\end{array}$ & Porto Alegre & Vol.7- No.2 & $\begin{array}{c}\text { Novembro } \\
2014\end{array}$ & p. 146-160 \\
\hline
\end{tabular}


A teoria da responsabilidade de Hans Jonas como resposta ética aos problemas levantados pela técnica moderna

em temor. Por isso mesmo, é possível afirmar que a nossa escolha por Hans Jonas como referencial teórico para pensarmos os problemas levantados pela técnica moderna se justifica pelo fato da abordagem filosófica deste autor se inserir na mesma rota de convergência da demanda atual, concernente ao risco de catástrofe a qual estará sujeito tanto o homem, como a biosfera inteira.

Tal cenário resulta da dominação humana da natureza, ao realizar o ideal baconiano, cujo saber confere ao homem o poder de dominar a natureza. A efervescência do debate atual em torno do "caos iminente", que se instala na esfera ambiental, já foi antecipado por Jonas na sua abordagem crítica sobre o advento das modernas tecnologias, bem como os efeitos nefastos por ela causados à natureza e ao próprio ser humano. Segue-se daí que o progresso tecnológico pode ameaçar à existência humana. E por isso mesmo, urge a necessidade de afirmação de um imperativo ético ancorado na metafísica, capaz de orientar o agir humano, diante dos desafios colocados pelo advento e alargamento do poder da técnica. Tais desafios dos tempos hodiernos apontam o prognóstico de um futuro catastrófico, razão pela qual se justifica a opção pelo projeto filosófico de Hans Jonas como referência teórica e orientadora para o presente estudo. Por se tratar de um autor, cujo pensamento pode ser aplicado aos problemas ambientais que ora enfrentamos, contribuindo, portanto, para a ampliação do debate, visando assim possíveis soluções. Em razão disso, o filósofo propõe a responsabilidade como princípio ético norteador do agir humano, diante dos problemas levantados pela tecnologia, mostrando como a teoria da responsabilidade pode se consubstanciar numa ordem ética por excelência. A filosofia de Hans Jonas não revelou apenas os efeitos da técnica do seu tempo, como também prefigurou o cenário que hoje faz ecoar e que ora assistimos e, concomitantemente, apontou o prognóstico do que estará sujeito à vida humana e à biosfera no futuro.

Em sua abordagem, Jonas revela sua preocupação com a continuidade da vida numa Terra modificada pelo advento da tecnologia. A constatação do autor, no entanto, mostra que cabe à geração atual a obrigação moral de velar pela possibilidade e continuidade da vida. Por um lado, o dever aumenta na proporção do conhecimento que temos de como é fácil destruir a vida. Por outro, o aumento do dever não se dá só em função do conhecimento, mas também de nosso poder-fazer. Ao propor o ensaio de uma ética para a civilização tecnológica, Jonas direciona o seu olhar para a imagem do homem no futuro. Destarte, o risco de destruição da vida é o ponto de partida para a investigação jonasiana, cuja ameaça apocalítica exige a formulação de uma ética de responsabilidade metafisicamente fundamentada, capaz de afirmar a imagem do homem no futuro.

Diante do atual cenário, Jonas propõe e fundamenta ontologicamente a categoria de responsabilidade como uma ordem ética, para destiná-la ao século XXI como princípio fundamental para salvaguardar a natureza das ações predatórias do ser humano. A situação do homem

\footnotetext{
${ }^{2}$ Segundo Hans Jonas, a possibilidade do "caos iminente" está atrelado a essa angustiosa homenagem ao opressivo poder humano, que narra a sua irrupção violenta e violentadora na ordem cósmica, a invasão atrevida dos diferentes domínios da natureza por meio de sua incansável esperteza. Cf. JONAS, H. O Princípio Responsabilidade: ensaio de uma ética para uma civilização tecnológica. Trad. Marijane Lisboa e Luiz Barros Montez. Rio de Janeiro: Contraponto, PUC Rio, 2006, p. 31.

\begin{tabular}{|c|c|l|l|l|l|}
\hline intuitio & $\begin{array}{c}\text { ISSN } \\
1983-4012\end{array}$ & Porto Alegre & Vol.7- $\mathrm{N}^{\mathrm{o} .2}$ & $\begin{array}{c}\text { Novembro } \\
2014\end{array}$ & p. 146-160 \\
\hline
\end{tabular}
}


A teoria da responsabilidade de Hans Jonas como resposta ética aos problemas levantados pela técnica moderna

contemporâneo mostra que nenhuma ética, até então, levou em consideração a possibilidade das ações humanas extinguirem do planeta a própria espécie. Tal situação, contudo, passou a exigir uma ética que permita, no presente, preservar a humanidade do futuro. Embora a teoria da responsabilidade como princípio ético na perspectiva jonasiana tenha como ponto nerval a continuidade da vida humana, tal teoria visa igualmente à vida extra-humana ${ }^{3}$. Por isso, torna-se compatível com as necessidades do homem na atual conjuntura tecnocientífica em que se encontra envolvida não apenas toda a humanidade, mas toda a biosfera. Por conseguinte, ao propor a teoria da responsabilidade para solucionar o problema da relação homem-natureza, Jonas responde a uma das importantes questões de nosso tempo, ou seja, a crise ambiental global e os efeitos, muitas vezes, irreversíveis de uma técnica posta em prática sem antes avaliar as consequências que poderão advir com tal prática. Assim, para todos que se empenham 'profeticamente' em salvar a vida na terra, a teoria da responsabilidade, como princípio ético, poderá oferecer caminhos possíveis.

No prefácio de sua principal obra, O princípio responsabilidade, o autor apresenta de forma sucinta o conteúdo fundamental do livro. Jonas usa a figura mitológica Prometeu numa analogia com o poder da ciência ${ }^{4}$ e também enuncia claramente as teses a serem desenvolvidas as quais fundamentam a teoria da responsabilidade. A saber:

\begin{abstract}
A técnica moderna transformou-se em ameaça ou a ameaça aliou-se à técnica; o vazio de que padece a nova práxis coletiva não é mais do que o vazio atual provocado pelo relativismo de valores; a ameaça que a 'heurística do medo' antecipa conscientiza o homem da ameaça suspensa, sobre a 'integridade da sua essência', ou seja, 'a imagem do homem'; se a integridade da essência do homem está em risco, impõe-se a fundamentação de uma ética forte que deve assemelhar-se ao aço e não ao algodão em rama ${ }^{5}$.
\end{abstract}

As teses acima enumeradas sublinham, a partir da perspectiva jonasiana, que existem limites para a civilização tecnocientífica, cuja relação desmedida que estabelece entre natureza e homem põe em risco a "precariedade do ser"6. Esta impõe ao homem a obrigação de guiar a sua ação por princípios éticos baseados na responsabilidade para com toda a biosfera e também para com as gerações vindouras.

\footnotetext{
${ }^{3}$ Aqui, não há especificidade de vidas, Jonas refere-se à condição da natureza extra-humana, isto é, a biosfera no todo e em suas partes, hoje subjugadas ao nosso poder, exatamente por isso não se tornaram um bem a nós confiados, capaz de nos impor algo como uma exigência moral. JONAS, H. O Princípio Responsabilidade: ensaio de uma ética para uma civilização tecnológica. Trad. Marijane Lisboa e Luiz Barros Montez. Rio de Janeiro: Contraponto, PUC Rio, 2006, p. 41.

4 "O Prometeu definitivamente desacorrentado, ao qual a ciência confere forças antes inimagináveis e a economia o impulso infatigável, clama por uma ética que, por meio de freios voluntários, impeça o poder dos homens de se transformar numa desgraça para eles mesmos". JONAS, H. O Princípio Responsabilidade: ensaio de uma ética para uma civilização tecnológica. Trad. Marijane Lisboa e Luiz Barros Montez. Rio de Janeiro: Contraponto, PUC Rio, 2006, p. 21.

${ }_{5}^{5}$ JONAS, H. O Princípio Responsabilidade: ensaio de uma ética para uma civilização tecnológica. Trad. Marijane Lisboa e Luiz Barros Montez. Rio de Janeiro: Contraponto, PUC Rio, 2006, p. 21-22.

${ }^{6}$ Jonas apresenta a precariedade do ser como centro da sua crítica ao advento da tecnologia, com efeito, é de fato a precariedade do ser que anima a formulação da teoria da responsabilidade.

\begin{tabular}{|c|c|l|l|l|l|}
\hline intuitio & $\begin{array}{c}\text { ISSN } \\
1983-4012\end{array}$ & Porto Alegre & Vol.7 $-\mathrm{N}^{\mathrm{o}} .2$ & $\begin{array}{c}\text { Novembro } \\
2014\end{array}$ & p. 146-160 \\
\hline
\end{tabular}
}


A teoria da responsabilidade de Hans Jonas como resposta ética aos problemas levantados pela técnica moderna

\section{A fundamentação metafísica da ética jonasiana}

Ao propor um novo princípio ético como resposta à civilização tecnológica, Jonas mostra por que a técnica moderna torna-se um problema filosófico e, concomitantemente, um problema ético, a partir do qual urge a necessidade da formulação de uma teoria da responsabilidade. No entanto, além de revelar o pressuposto e o significado de sua teoria ética, nosso autor destaca também os elementos que a compõem, isto é, as bases filosóficas nas quais tal teoria se apoia. Já na apresentação da principal obra de Hans Jonas, $O$ princípio responsabilidade, podemos identificar as categorias em torno das quais a elaboração da teoria da responsabilidade seria construída:

Em torno das categorias de bem, de dever e de ser e encontraria na relação paisfilhos seu arquétipo primordial. A adequação entre o ser e o "dever ser" tem sido tarefa primordial na história da humanidade desde seus primórdios. [...] Hans Jonas apresenta o entrelaçamento dessas três categorias como base de configuração da ética nova ${ }^{7}$.

Portanto, é na esteira dessas três categorias, o bem, o dever e o ser, que Jonas propõe a teoria da responsabilidade e, concomitantemente, é em torno desses elementos que o filósofo traz à lume as questões da ligação do ser ao dever-ser, da causa e da finalidade da natureza e do valor para enraizar no ser o novo dever do homem - a responsabilidade.

Como se vê, o objeto de estudo desta apreciação consiste na investigação sobre a necessidade e relevância da teoria da responsabilidade proposta pelo nosso filósofo. Contudo, é nossa intenção também, além de apresentar o significado e alcance da temática, explicitar a fundamentação metafísica como condição de possibilidade de compreensão da teoria ética de Jonas. Já que a teoria da responsabilidade tem sua sede em hipóteses ontológicas, isto é, o bem, o dever e o ser, Jonas nos mostra a partir disso que somente a compreensão científica dos fatos não pode ser a última palavra sobre todos os organismos vivos ${ }^{8}$. Pois o ser, em todas as suas dimensões, resulta em um dever. Entendemos que o bem se torna um dever quando existe vontade na execução da ação. Sendo assim, do bem pode originar uma incumbência, pois "com isso, torna-se um dever, desde que seja uma vontade que assuma essa exigência e trate de realizá-la"9. O dever que resulta do ser não é compreendido por dedução lógica, de certo modo, podemos deduzir o dever do ser, mas na esfera existencial e não um dever prescrito. Há, portanto, uma vontade deliberada que legisla perante o ser, capaz de responder à exigência de um dever.

\footnotetext{
7 JONAS, H. O Princípio Responsabilidade: ensaio de uma ética para uma civilização tecnológica. Trad. Marijane Lisboa e Luiz Barros Montez. Rio de Janeiro: Contraponto, PUC Rio, 2006, p. 19.

${ }^{8}$ Aqui é necessária uma aclaração, pois, ao se referir aos organismos vivos, Jonas embora esteja englobando a vida em seu conjunto, há um acento na primazia do ser humano em relação aos outros seres. Tal primazia, no entanto, apoia-se no fato do ser humano ser o porta voz do dever, uma que vez que, é do ser do homem que resulta o dever-ser.

9 JONAS, H. O Princípio Responsabilidade: ensaio de uma ética para uma civilização tecnológica. Trad. Marijane Lisboa e Luiz Barros Montez. Rio de Janeiro: Contraponto, PUC Rio, 2006, p.. 149.

\begin{tabular}{|c|c|c|c|c|c|}
\hline intuitio & $\begin{array}{c}\text { ISSN } \\
1983-4012\end{array}$ & Porto Alegre & Vol.7- No.2 & $\begin{array}{c}\text { Novembro } \\
2014\end{array}$ & p. 146-160 \\
\hline
\end{tabular}
}


A teoria da responsabilidade de Hans Jonas como resposta ética aos problemas levantados pela técnica moderna

Assim, é necessário a articulação das categorias heurística do medo, fim e valor, bem, o dever $e$ o ser e a relação entre a responsabilidade paterna, política e total, para criar a base de uma configuração ética que fundamente a teoria da responsabilidade. Segundo Jonas, a ética precisa ser fundamentada na totalidade do ser, mas também fundamentada na singularidade do homem, buscando sempre evitar qualquer forma de relativismo de valores. A teoria da responsabilidade é também um imperativo da existência, e esta seria a primeira condição de uma ética responsável com e pelo mundo de amanhã.

Hans Jonas demonstra, por um lado, uma preocupação a favor da vida, especialmente com a humana e com a 'imagem do homem no futuro'. Por outro lado, igualmente afirma a urgência no que diz respeito à opção pela biodiversidade que se encontra em toda a natureza. "Mais do que uma extensão do espectro genérico, o interesse se manifesta na intensidade dos fins próprios dos seres vivos, nos quais a finalidade da natureza se torna cada vez mais sugestiva" ${ }^{\prime 10}$. Ao propor o argumento teleológico da natureza, Jonas pretende mostrar que os seres vivos devem viver para cumprir um objetivo, mesmo que seja consigo mesmos.

Jonas entende o bem como pertencente à realidade do ser, pois lhe é próprio e poderá transformar-se em dever na medida em que exista uma vontade capaz de transformá-lo em ação. Esta compreensão fundamenta a teoria da responsabilidade "como exigência pertencente à realidade do ser, direcionada à preservação da vida" 11 . O dever é uma exigência que está implícita no ser. Na intenção de fundamentar ontologicamente a sua teoria ética, Jonas apoia-se na primazia do ser em relação ao nada. A preferência pelo ser ao invés do nada conduz, então, à ética da responsabilidade à sua base inaugural e ainda mais primordial. Dirigido ao futuro, o princípio responsabilidade se situa num campo novo no qual a ética prescinde de um conceito funcional por ela amplamente utilizado - a reciprocidade. ${ }^{12}$ De acordo com Jonas, "a ideia tradicional de direitos e deveres" ${ }^{13}$ não é mais suficiente para fundamentar a nova ética porque não há um outro presentificado no tempo ou no espaço, cujo direito ou dever sirva de bússola orientadora ou reflexo invertido para si. A proposta jonasiana postula que "o sujeito moral deve considerar objeto de sua responsabilidade seres humanos futuros, ou seja, seres que ainda não são e que, portanto, a partir de uma ótica tradicional, não têm direitos e nem podem exercer seus deveres"14. Para Jonas, o dever com a existência futura depende exclusivamente de nossa responsabilidade. Se somos responsáveis pelo ser, somos responsáveis pelo futuro que ainda não existe, mas que está projetado pela continuidade do direito de ser e estar no mundo.

\footnotetext{
${ }^{10}$ JONAS, H. JONAS, H. O Princípio Responsabilidade: ensaio de uma ética para uma civilização tecnológica. Trad. Marijane Lisboa e Luiz Barros Montez. Rio de Janeiro: Contraponto, PUC Rio, 2006, p. 251.

${ }^{11}$ SÈVE, B. Hans Jonas et l'ethique de la responsabilité, p. 11.

${ }^{12}$ Cf. OLIVEIRA, J. R. De. Por que uma ética do futuro precisa de uma fundamentação metafísica, p. 397.

${ }^{13}$ JONAS, H. O Princípio Responsabilidade: ensaio de uma ética para uma civilização tecnológica. Trad. Marijane Lisboa e Luiz Barros Montez. Rio de Janeiro: Contraponto, PUC Rio, 2006, p. 89.

${ }^{14}$ COMÍN, G. I. Introd.. In: JONAS, H. Poder o impotencia de la subjetividade, p. 25.

\begin{tabular}{|c|c|c|c|c|c|}
\hline intuitio & $\begin{array}{c}\text { ISSN } \\
1983-4012\end{array}$ & Porto Alegre & Vol.7 - N .2 & $\begin{array}{c}\text { Novembro } \\
2014\end{array}$ & p. 146-160 \\
\hline
\end{tabular}
}


A teoria da responsabilidade de Hans Jonas como resposta ética aos problemas levantados pela técnica moderna

Da articulação entre bem, o dever e o ser emerge a teoria da responsabilidade, cuja compreensão resulta da pergunta a qual gira em torno do valor do ser: "a pergunta pelo dever ser implica que o ser se dote de valores, se entenda como um bem, de maneira que o ser se converta em um imperativo, em um dever fazer para que o ser realmente possa ser e possa seguir sendo, porque o ser é um valor e um bem em si" ". Para Jonas, o valor ou mesmo o "bem" é algo que reivindica imediatamente a sua existência, ou seja, o que vale (como "bem") é o que merece existir, tanto no que tange à reivindicação pelo Ser pela via de um dever-ser que se transforma num certo agir ${ }^{16}$, "no caso em que o Ser dependa da livre escolha desse agir" ${ }^{\prime 17}$.

Como se percebe, a teoria ética de Jonas encontra sua sede na articulação entre o bem, o dever e o ser. De tal relação, o autor empreende o esforço argumentativo na busca do significado da responsabilidade como princípio ético. Com isso, destacamos mais um passo deste nosso estudo, isto é, investigar a maneira pela qual Jonas articula as categorias de bem, ser e dever ser, que compõem a teoria da responsabilidade. Partindo do princípio de que Jonas busca elementos ontológicos que fundamentam a ética da responsabilidade, não podemos deixar de destacar que tal teoria, objeto deste estudo, assenta na condição ontológica do ser que fundamenta um dever-ser em proveito da responsabilidade à totalidade orgânica, conferindo uma teleologia à natureza e o respeito à vida como alvo de uma ética entendida como parte da vida. A totalidade enquanto objeto acarreta valor, resultando numa fundamentação que prioriza a ética e seu elemento central: a vida. A totalidade orgânica do ser nos exorta à responsabilidade pelo futuro. O dever ser de algo implica fazer algo e é nessa esteira que a responsabilidade toma sentido enquanto princípio. Portanto, visto que com o homem o poder se emancipou de tudo mediante o saber, ele torna-se por conta disso, fatal para a existência. Assim, em nome do princípio responsabilidade, o homem é objeto primeiro do dever deslocando a responsabilidade para o centro da ética ${ }^{18}$. E o porquê de a responsabilidade estar no centro da teoria ética de Jonas, igualmente, é alvo deste nosso estudo.

A responsabilidade até hoje não esteve totalmente no centro das teorias morais tradicionais, já que todos os mandamentos e máximas da "antiga" moral (apontam), para "o caráter imediato da ação. Ama o teu próximo como a ti mesmo; faz aos outros o que gostarias que fizessem a ti"," A ética tradicional era marcada pelo caráter antropocêntrico, ou seja, reduzida ao âmbito interno do sujeito,

\footnotetext{
${ }^{15}$ COMÍN, G. I. Introd. In: JONAS, H. Poder o impotência de la subjetividade, p. 42.

${ }^{16}$ Cf. OLIVEIRA, J. R. de. Por que uma ética do futuro precisa de uma fundamentação metafísica. p. 404.

${ }^{17}$ JONAS, H. O Princípio Responsabilidade: ensaio de uma ética para uma civilização tecnológica. Trad. Marijane Lisboa e Luiz Barros Montez. Rio de Janeiro: Contraponto, PUC Rio, 2006, p. 102.

${ }^{18} \mathrm{O}$ homem como objeto do dever inclui a responsabilidade no centro da ética, assegurando uma autenticidade humana, garantindo ao homem sua capacidade de escolha: "precisamente a preservação dessa possibilidade, como responsabilidade 'cósmica', é o que significa dever de existência. Exagerando, caberia dizer que a possibilidade de que haja responsabilidade é a responsabilidade que precede a tudo" (JONAS, H. O Princípio Responsabilidade: ensaio de uma ética para uma civilização tecnológica. Trad. Marijane Lisboa e Luiz Barros Montez. Rio de Janeiro: Contraponto, PUC Rio, 2006, p. 174).

${ }^{19}$ JONAS, H. O Princípio Responsabilidade: ensaio de uma ética para uma civilização tecnológica. Trad. Marijane Lisboa e Luiz Barros Montez. Rio de Janeiro: Contraponto, PUC Rio, 2006, p. 36.
}

\begin{tabular}{|c|c|c|c|c|c|}
\hline intuitio & $\begin{array}{c}\text { ISSN } \\
1983-4012\end{array}$ & Porto Alegre & Vol.7 - No.2 & $\begin{array}{c}\text { Novembro } \\
2014\end{array}$ & p. 146-160 \\
\hline
\end{tabular}


A teoria da responsabilidade de Hans Jonas como resposta ética aos problemas levantados pela técnica moderna "concentrando-se toda a atenção em como agir corretamente em relação ao aqui e agora"20. O agir ético se restringia ao presente, não havia, portanto, uma preocupação com o porvir a longo prazo. "A única preocupação em relação às futuras gerações consistia tão somente na repetição dos fundamentos das primeiras gerações" ${ }^{\text {21 }}$. Ao contrário das éticas anteriores, a responsabilidade de Hans Jonas está no centro de sua teoria ética, uma vez que com tal teoria ele quer fundar uma proposta capaz de inaugurar uma reflexão profunda sobre o papel do homem contemporâneo na condução dos destinos do planeta. Tal empresa heuristicamente leva o homem a proteger a natureza frente às suas ações, proteger o homem de si mesmo e, assim, a própria natureza humana. Segundo Jonas, "a simples existência de um ser "ôntico" contém intrinsecamente, e de forma evidente um dever para outros" 22 . Para Jonas, buscar um princípio que fundamente o agir moral do homem contemporâneo é abrir um diálogo sobre a possibilidade da permanência de um mundo viável, no futuro.

De acordo com Hans Jonas, o ser humano por si só já tem um valor fundamental pela totalidade do seu ser, tendo uma vantagem em relação aos outros seres pelo fato de poder assumir responsabilidades, podendo assim, garantir seus próprios fins. É a partir deste momento que surge o arquétipo de toda a responsabilidade do homem, baseada na natureza das coisas, na relação do sujeito e objeto, porém, essa relação ocorre somente com a existência do espaço e do tempo. Segundo Jonas,

A marca distintiva do ser humano, de ser o único capaz de ter responsabilidade, significa igualmente que ele deve tê-la pelos seus semelhantes, eles próprios, potenciais sujeitos de responsabilidade, e que realmente ele sempre a tem, de um jeito ou de outro: a faculdade para tal é a condição suficiente para a sua efetividade. Ser responsável efetivamente por alguém ou por qualquer coisa em certas circunstâncias (mesmo que não assuma e nem reconheça tal responsabilidade) é tão inseparável da existência do homem quanto o fato de que ele seja genericamente capaz de responsabilidade da mesma maneira que lhe é inalienável a sua natureza falante, característica fundamental para a sua definição, caso deseje empreender essa duvidosa tarefa ${ }^{23}$.

Em outras palavras, podemos compreender que "há um dever contido no ser" do homem. Em razão disso, diz Jonas, o homem ainda não é moral, mas um "Ser capaz de ser moral ou imoral" 24 . Segue-se daí que por um lado, num primeiro momento, o imperativo continua sendo a "própria existência". Por outro lado, sob o ponto de vista do poder da ação, isto é, do nosso poder fazer numa perspectiva de exteriorização, a responsabilidade se torna um princípio ético ${ }^{25}$, voltado para outros.

\footnotetext{
${ }^{20}$ JONAS, H. O Princípio Responsabilidade: ensaio de uma ética para uma civilização tecnológica. Trad. Marijane Lisboa e Luiz Barros Montez. Rio de Janeiro: Contraponto, PUC Rio, 2006, p. 209.

${ }^{21}$ JONAS, H. O Princípio Responsabilidade: ensaio de uma ética para uma civilização tecnológica. Trad. Marijane Lisboa e Luiz Barros Montez. Rio de Janeiro: Contraponto, PUC Rio, 2006, p. 209.

22 JONAS, H. O Princípio Responsabilidade: ensaio de uma ética para uma civilização tecnológica. Trad. Marijane Lisboa e Luiz Barros Montez. Rio de Janeiro: Contraponto, PUC Rio, 2006, p. 220.

${ }^{23}$ JONAS, H. O Princípio Responsabilidade: ensaio de uma ética para uma civilização tecnológica. Trad. Marijane Lisboa e Luiz Barros Montez. Rio de Janeiro: Contraponto, PUC Rio, 2006, pp. 175-176.

${ }^{24}$ JONAS, H. O Princípio Responsabilidade: ensaio de uma ética para uma civilização tecnológica. Trad. Marijane Lisboa e Luiz Barros Montez. Rio de Janeiro: Contraponto, PUC Rio, 2006, p. 176.

${ }^{25}$ Cf. OLIVEIRA, J. R. De. Por que uma ética do futuro precisa de uma fundamentação metafísica. pp. 399400.

\begin{tabular}{|c|c|c|c|c|c|}
\hline intuitio & $\begin{array}{c}\text { ISSN } \\
1983-4012\end{array}$ & Porto Alegre & Vol.7 - N .2 & $\begin{array}{c}\text { Novembro } \\
2014\end{array}$ & p. 146-160 \\
\hline
\end{tabular}
}


A teoria da responsabilidade de Hans Jonas como resposta ética aos problemas levantados pela técnica moderna

Sendo assim, a responsabilidade está contida no homem como condição ontológica e como dever do ser. Já que a responsabilidade consiste num dever do ser, como condição de possibilidade da 'reserva ética' no futuro, podemos então compreender que a ética do futuro trata de um não ser ainda para o qual seria necessário falar de um direito a ser respeitado, não se conformando com a ausência de reivindicação por parte deste ser que ainda não é ${ }^{26}$.

\section{A responsabilidade parental e política: dois modelos}

Jonas afirma já existir na moral "um caso de responsabilidade e obrigação elementar não recíproca (que comove profundamente o simples espectador) e que é reconhecido e praticado espontaneamente" 27 , ou seja, a responsabilidade dos pais para com os filhos. Na perspectiva jonasiana, nessa relação o pai é responsável pela prole independente da ideia de reciprocidade e garante precaução e assistência sem que essas sejam reivindicadas pelos filhos e sem esperar recompensas como precondição para os seus esforços. Nesse caso, a responsabilidade é incondicional e se estabelece como "única classe de comportamento inteiramente altruísta fornecida pela natureza" 28 .

A esta responsabilidade, Jonas define como responsabilidade paterna, cuja condição de possibilidade emerge da relação natural, incondicional, englobando a totalidade do objeto, não dependendo de aprovação prévia. Enquanto o outro modelo paradigmático da responsabilidade, a saber, a responsabilidade política, Jonas definiu como sendo fruto de uma escolha, ambicionando o poder para exercer a responsabilidade suprema. O filósofo destaca a importância fundamental da responsabilidade paterna e política:

A essa altura, pode ser do maior interesse teórico examinar como essa responsabilidade nascida da livre escolha e aquela decorrente da menos livre das relações naturais, ou seja, a responsabilidade do homem público e a dos pais, que se situam nos extremos do espectro da responsabilidade, são as que têm mais aspectos em comum entre si e as que, em conjunto, mais nos podem ensinar a respeito da essência da responsabilidade ${ }^{29}$.

Para Jonas, quando a criança adquire conhecimentos de linguagens, ela aprende normas, códigos sociais que estão implícitos nas normas estabelecidas no processo educativo. No entanto, a esfera política tem o dever de assumir a educação dos filhos e os pais, nesse caso, terão que confiar no Estado. A responsabilidade política é ampla, pois trabalha com espaços maiores na perspectiva histórica. Já a responsabilidade paterna é centrada no desenvolvimento individual da criança. A

\footnotetext{
${ }^{26}$ JONAS, H. O Princípio Responsabilidade: ensaio de uma ética para uma civilização tecnológica. Trad. Marijane Lisboa e Luiz Barros Montez. Rio de Janeiro: Contraponto, PUC Rio, 2006, p. 398.

${ }^{27}$ JONAS, H. O Princípio Responsabilidade: ensaio de uma ética para uma civilização tecnológica. Trad. Marijane Lisboa e Luiz Barros Montez. Rio de Janeiro: Contraponto, PUC Rio, 2006, p. 89.

${ }^{28}$ JONAS, H. O Princípio Responsabilidade: ensaio de uma ética para uma civilização tecnológica. Trad. Marijane Lisboa e Luiz Barros Montez. Rio de Janeiro: Contraponto, PUC Rio, 2006, p. 89.

${ }^{29}$ JONAS, H. O Princípio Responsabilidade: ensaio de uma ética para uma civilização tecnológica. Trad. Marijane Lisboa e Luiz Barros Montez. Rio de Janeiro: Contraponto, PUC Rio, 2006, p. 173
}

\begin{tabular}{|c|c|c|c|c|c|}
\hline intuitio & $\begin{array}{c}\text { ISSN } \\
1983-4012\end{array}$ & Porto Alegre & Vol.7- No.2 & $\begin{array}{c}\text { Novembro } \\
2014\end{array}$ & p. 146-160 \\
\hline
\end{tabular}


A teoria da responsabilidade de Hans Jonas como resposta ética aos problemas levantados pela técnica moderna

responsabilidade política e paterna têm o poder de decisões em relação à vida para sua continuidade no presente, sobretudo, no futuro. Justamente por isso, tais responsabilidades não podem deixar de estar presente e nem podem serem interrompidas. Segundo Jonas,

As assistências paterna e governamental não podem tirar férias, pois a vida do seu objeto segue em frente, renovando as demandas ininterruptamente. Mais importante é a continuidade dessa existência assistida como uma preocupação, que ambas as responsabilidades aqui analisadas necessitam considerar em cada oportunidade de atuação. As responsabilidades particulares não se limitam apenas a um aspecto, mas também a um período determinado de uma existência ${ }^{30}$.

Hans Jonas utiliza exemplos para demonstrar as responsabilidades e particularidades de cada situação vivida. Um deles aponta que o capitão de um barco não tem interesse em saber de onde vieram seus passageiros e muito menos para onde vão depois de chegar ao destino programado. A tarefa do capitão consiste unicamente em transportar os seus passageiros com vida, segurança e responsabilidade. Para Jonas, "nesse aspecto, a responsabilidade política tem uma dimensão muito

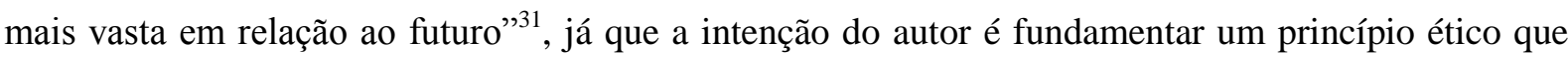
reserve o direito de ser do homem no futuro. Outro exemplo menciona a forma com que o médico conduz o tratamento de um paciente. A responsabilidade de um médico com o seu paciente termina quando o paciente finaliza o seu tratamento e obtém a cura. Para o médico, "não lhe interessam os outros prazeres e sofrimentos que têm significado para aquela vida que ele salvou, sua responsabilidade termina com o fim do tratamento" ${ }^{32}$. Para termos uma responsabilidade total e não parcial das situações vividas, devemos ter como critérios as seguintes indagações:

O que vem agora? Para onde vamos? E em seguida, o que houve antes? Como se liga o que está ocorrendo agora com o desenrolar da existência? Em uma palavra, a responsabilidade total tem de proceder de forma "histórica", aprender seu objeto na sua historicidade. Esse é o sentido preciso do elemento que caracterizamos aqui como continuidade ${ }^{33}$.

Nesse aspecto, percebemos o quanto a responsabilidade política tem uma dimensão ampla na dimensão histórica. A preocupação fundamental neste momento está voltada ao futuro, pois implica a continuidade de uma identidade a qual integra diretamente a responsabilidade coletiva. Entretanto, na responsabilidade paterna existe uma preocupação voltada ao indivíduo, como, por exemplo, a criança adquire uma identidade histórica a partir de sua historicidade individual. É essa identidade histórica sobre o tempo que, para Jonas, pode ser desenvolvida e garantida pela educação, pois ocorre uma passagem da responsabilidade paterna para o mundo histórico. $\mathrm{O}$ processo de responsabilidade total

${ }^{30}$ JONAS, H. O Princípio Responsabilidade: ensaio de uma ética para uma civilização tecnológica. Trad. Marijane Lisboa e Luiz Barros Montez. Rio de Janeiro: Contraponto, PUC Rio, 2006, p. 185.

31 JONAS, H. O Princípio Responsabilidade: ensaio de uma ética para uma civilização tecnológica. Trad. Marijane Lisboa e Luiz Barros Montez. Rio de Janeiro: Contraponto, PUC Rio, 2006, p. 185.

32 JONAS, H. O Princípio Responsabilidade: ensaio de uma ética para uma civilização tecnológica. Trad. Marijane Lisboa e Luiz Barros Montez. Rio de Janeiro: Contraponto, PUC Rio, 2006, p. 185

33 JONAS, H. O Princípio Responsabilidade: ensaio de uma ética para uma civilização tecnológica. Trad. Marijane Lisboa e Luiz Barros Montez. Rio de Janeiro: Contraponto, PUC Rio, 2006, p. 185.

\begin{tabular}{|c|c|c|c|c|c|}
\hline intuitio & $\begin{array}{c}\text { ISSN } \\
1983-4012\end{array}$ & Porto Alegre & Vol.7- No.2 & $\begin{array}{c}\text { Novembro } \\
2014\end{array}$ & p. 146-160 \\
\hline
\end{tabular}


A teoria da responsabilidade de Hans Jonas como resposta ética aos problemas levantados pela técnica moderna

via educação inicia na esfera individual, todavia o telos o qual tal teoria vislumbra consiste no nível social, isto é, o todo sem correr o risco de perder a identidade histórica. Desta forma, Jonas entende que:

Todo educador sabe disso. Mas, além disso, e de forma inseparável encontra-se a comunicação da tradição coletiva, com o seu primeiro som articulado e a preparação para a vida em sociedade. Com isso, o horizonte da continuidade amplia-se no mundo histórico; uma se sobrepõe à outra, e assim é impossível à responsabilidade educativa deixar de ser "política", mesmo no mais privado dos âmbitos ${ }^{34}$.

A responsabilidade, seja ela por vias individuais ou coletivas, deverá ocupar-se com a vida, com o hoje e o mundo de amanhã. "Mas essa óbvia inclusão do amanhã no hoje, que tem a ver com a temporalidade como tal, adquire uma dimensão e uma qualidade nova no contexto da responsabilidade total”35. A responsabilidade total inclui a existência da vida futura, ao contrário dos exemplos anteriores, em que o médico e o capitão do barco não têm como princípio preocupações o que não envolve as suas responsabilidades momentânea, pois não passam de exemplos de uma "responsabilidade parcial”. Já a responsabilidade paterna tem como fim pré-determinado educar para tornar o filho adulto e responsável, ou seja, tem inclusa uma das grandes tarefas da vida, que é cuidar da vida. Nenhuma criança pede para nascer em determinadas situações privilegiadas. Porém, "com cada criança que nasce recomeça a humanidade em face da mortalidade, e nesse sentido também está em jogo a sobrevivência da humanidade" ${ }^{\text {,36 }}$ abrindo um caminho para o recomeçar e possibilitando a continuidade da existência de vidas no mundo de amanhã.

De fato, quando a tarefa se reserva ao político a responsabilidade se faz presente, contudo, é apenas sua exterioridade que reside na responsabilidade do homem escolhido para governar de forma responsável. Assim, da mesma forma, o homem enquanto ser vivo é condição necessária, porém não suficiente. Ele é o destino da responsabilidade e, concomitantemente, a sua gênese. Devemos sublinhar que essa analogia permite a Jonas comparar e admitir uma coalização, uma interidentificação entre a responsabilidade parental e a responsabilidade do homem público - político. Dado que a responsabilidade abarca o ser total do objeto e a responsabilidade política e parental se fundem em seu caráter próprio de responsabilidade mesmo envolvendo cada um o seu dever. $\mathrm{Na}$ responsabilidade parental, "seu objeto é a criança como um todo e todas as suas possibilidades [...]"37, enquanto a responsabilidade do político estabelece sua relação com o espaço público e a determinação do que o Estado pode contribuir para, por exemplo, na esfera da educação, entendida como um benefício do Estado, qual política educacional mais eficiente. Nessa combinação, a esfera do privado

${ }^{34}$ JONAS, H. O Princípio Responsabilidade: ensaio de uma ética para uma civilização tecnológica. Trad. Marijane Lisboa e Luiz Barros Montez. Rio de Janeiro: Contraponto, PUC Rio, 2006, p. 186.

35 JONAS, H. O Princípio Responsabilidade: ensaio de uma ética para uma civilização tecnológica. Trad. Marijane Lisboa e Luiz Barros Montez. Rio de Janeiro: Contraponto, PUC Rio, 2006, p. 186.

${ }^{36}$ JONAS, H. O Princípio Responsabilidade: ensaio de uma ética para uma civilização tecnológica. Trad. Marijane Lisboa e Luiz Barros Montez. Rio de Janeiro: Contraponto, PUC Rio, 2006, p. 224.

${ }^{37}$ Cf. JONAS, H. O Princípio Responsabilidade: ensaio de uma ética para uma civilização tecnológica. Trad. Marijane Lisboa e Luiz Barros Montez. Rio de Janeiro: Contraponto, PUC Rio, 2006, p. 180.

\begin{tabular}{|c|c|l|l|l|l|}
\hline intuitio & $\begin{array}{c}\text { ISSN } \\
1983-4012\end{array}$ & Porto Alegre & Vol.7 $-\mathrm{N}^{\mathrm{o}} .2$ & $\begin{array}{c}\text { Novembro } \\
2014\end{array}$ & p. 146-160 \\
\hline
\end{tabular}


A teoria da responsabilidade de Hans Jonas como resposta ética aos problemas levantados pela técnica moderna

se alarga em direção ao público, invocando a responsabilidade do homem público. Além disso, Jonas percebe nos dois tipos de responsabilidade uma analogia quanto ao sentimento ${ }^{38}$.

O percurso argumentativo de Jonas na formulação da teoria da responsabilidade deve ser compreendido a partir das seguintes distinções: a responsabilidade não deve ser compreendida como reciprocidade, nem como responsabilidade jurídica. A negativa de Jonas em relação ao aspecto recíproco apoia-se na compreensão de que a responsabilidade como dever do ser revela-se na ação eficaz do ser humano para com os outros apenas no hoje da história, não cedendo espaço para que o amanhã possa ser pensado no hoje. Já o aspecto jurídico é marcado pelo caráter "contratual, pela tarefa acordada ou ordenada"39 sem, portanto, considerar o dever ser do qual emerge a consciência e o sentimento de responsabilidade. Em outras palavras, a responsabilidade é vista pelo autor a partir da analogia daquela do pai para com seu filho e a do político em relação a seus governados. Para Jonas, a responsabilidade enquanto uma imputação causal de atos feitos por um indivíduo, num primeiro momento, pode ser compreendida como uma responsabilidade restrita ao plano jurídico. Aquele que causa um dano deve ser imputado a reparar o dano cometido. Ocorre que, enquanto causalidade de ações e reparos, a responsabilidade fica restrita a uma exterioridade e a culpa não se efetiva de forma ética. Jonas deixa de lado a causalidade moral dos atos "assim, o que é decisivo nesse caso para a imputação da responsabilidade é a qualidade, e não a causalidade do ato" ${ }^{\text {"40 }}$.

A responsabilidade pelas gerações futuras e pelo todo orgânico demanda, em termos morais, uma atenção especial com o poder-fazer, que o indivíduo possui enquanto 'ser' responsável. Com Jonas, podemos propor uma releitura da máxima existencialista sublinhando a responsabilidade estamos condenados a ser responsáveis. Dessa responsabilidade "brota o amor pelo que não esta aí 'ainda' apontando uma ética futura” ${ }^{41}$. Agir já nos impõe a moralidade, e agir de forma irresponsável representa a não observância do dever que cabe ao agente. Por isso, para Jonas, a responsabilidade não pode ser uma relação recíproca, pois tal relação nos move apenas no hoje da história, isto é, no aqui agora, o que inviabiliza a ação responsável pelo todo, mormente no futuro. A urgência de uma ética da responsabilidade em ralação ao futuro nos impõe o imperativo da consciência como condição de possibilidade de superação da estrutura artificial, contratual e jurídica, que orienta o agir humano nos tempos hodiernos. Tal consciência, por sua vez, reserva ao homem somente a responsabilidade do

\footnotetext{
${ }^{38}$ Essas duas responsabilidades apontam a condição do sujeito e a partir disso podemos compreender o estatuto dos sentimentos morais para Jonas notadamente a solidariedade. Esse sentimento aponta para o amor universal, pois "é difícil, senão impossível, assumir a responsabilidade por algo que não se ame, de modo que é mais fácil engendrar o amor para tal do que cumprir o seu dever [...]" Cf. JONAS, H. O Princípio Responsabilidade: ensaio de uma ética para uma civilização tecnológica. Trad. Marijane Lisboa e Luiz Barros Montez. Rio de Janeiro: Contraponto, PUC Rio, 2006, p. 183.

39 JONAS, H. O Princípio Responsabilidade: ensaio de uma ética para uma civilização tecnológica. Trad. Marijane Lisboa e Luiz Barros Montez. Rio de Janeiro: Contraponto, PUC Rio, 2006, p. 171.

${ }^{40}$ JONAS, H. O Princípio Responsabilidade: ensaio de uma ética para uma civilização tecnológica. Trad. Marijane Lisboa e Luiz Barros Montez. Rio de Janeiro: Contraponto, PUC Rio, 2006, p. 166.

${ }^{41}$ Cf. JONAS, H. O Princípio Responsabilidade: ensaio de uma ética para uma civilização tecnológica. Trad. Marijane Lisboa e Luiz Barros Montez. Rio de Janeiro: Contraponto, PUC Rio, 2006, p. 168.
}

\begin{tabular}{|c|c|c|c|c|c|}
\hline intuitio & $\begin{array}{c}\text { ISSN } \\
1983-4012\end{array}$ & Porto Alegre & Vol.7 - No.2 & $\begin{array}{c}\text { Novembro } \\
2014\end{array}$ & p. 146-160 \\
\hline
\end{tabular}


A teoria da responsabilidade de Hans Jonas como resposta ética aos problemas levantados pela técnica moderna

dever natural pelo futuro da humanidade e de toda biosfera, pois, segundo Jonas seu caráter é "[ [...] irrevogável e não-rescindível, além de englobar a totalidade do objeto ${ }^{\text {"42 }}$.

\section{Considerações finais}

Nosso estudo procurou mostrar em que medida a teoria da responsabilidade, proposta por Hans Jonas, pode se consubstanciar numa nova ordem ética capaz de orientar o agir humano frente aos problemas levantados pela técnica moderna. A realização de tal empresa, no entanto, demandou três passos. Primeiro, mostramos por que para Jonas a técnica moderna é objeto da filosofia e, por que o advento da técnica na contemporaneidade coloca um problema para a ética. Ao analisar tais questões, Jonas chegou a uma constatação, qual seja a urgência da formulação de uma teoria da responsabilidade como um novo princípio ético que oriente o homem de hoje à preservação da integridade e essência humana das gerações vindouras. Se por um lado, mostramos o pressuposto, a necessidade e o significado da teoria ética de Jonas, por outro, no segundo passo apresentamos as bases metafísicas nas quais se apoiam à ética jonasiana. Segundo Jonas, a ética do futuro metafisicamente fundamentada resulta da articulação das categorias de bem, dever e o ser. O dever é fundado no ser, seguindo-se daí que a responsabilidade emerge como o novo dever do homem. Finalmente, no terceiro passo destacamos responsabilidade política e a aquela dos pais para com os filhos como modelos nos quais se aplicam a responsabilidade proposta por Jonas. Portanto, à luz da abordagem filosófica de Hans Jonas, sobre a necessidade de uma teoria ética ontologicamente fundamentada, diante dos desafios levantados pela técnica moderna, e considerando a relevância dada por ele ao tema, concluo e ao mesmo tempo deixo em aberto a possibilidade de ampliação dessa discussão com a seguinte pergunta: será a Teoria da responsabilidade apta a engendrar uma nova ordem ética capaz de orientar o agir humano, de modo a superar a ameaça de extinção da espécie e reconduzi-la para a perspectiva de continuidade na espera pelas gerações vindouras?

\section{Referências}

JONAS, Hans. O Princípio Responsabilidade: ensaio de uma ética para uma civilização tecnológica. Trad. Marijane Lisboa e Luiz Barros Montez. Rio de Janeiro: Contraponto, PUC Rio, 2006. JONAS, H. Técnica, medicina e ética: sobre a prática do princípio responsabilidade. Trad. grupo de trabalho Hans Jonas da ANPOF. (Associação Nacional de pós-graduação em Filosofia), São Paulo: Paulus, 2013.

On Faith reason and Responsability (1978), The Institute for Antiquity and Christamity, $2^{\mathrm{a}}$ ed., Clanemont, California, 1981.

La Science comme vécu Personnel. Trad. de Robert Brisart do título original Wissenschaft ais personliches Erlebnis (1987), in rev. Études phénoménologiques, tomo IV, nº 8, 1998, OUSIA, Bruxelas, p. 932.

42 JONAS, H. O Princípio Responsabilidade: ensaio de uma ética para uma civilização tecnológica. Trad. Marijane Lisboa e Luiz Barros Montez. Rio de Janeiro: Contraponto, PUC Rio, 2006, p. 170.

\begin{tabular}{|c|c|c|c|c|c|}
\hline intuitio & $\begin{array}{c}\text { ISSN } \\
1983-4012\end{array}$ & Porto Alegre & Vol.7 - N .2 & $\begin{array}{c}\text { Novembro } \\
2014\end{array}$ & p. 146-160 \\
\hline
\end{tabular}


A teoria da responsabilidade de Hans Jonas como resposta ética aos problemas levantados pela técnica moderna

Pour une Ethique du Futur. Trad. de Sabine Cornille et Philippe Ivernel dos títulos originais "Philosophie. Riickschau und Vorschau am Ende des Jahrhunderts (1993)" extraído de "Philosophische Untersuchungen und metaphysische Vermutungen”, Rivages Poche, Paris, 1998.

Vozes, 2004.

O princípio vida: fundamentos para uma biologia filosófica. Trad. Carlos Almeida Pereira. Petrópolis:

Por que a técnica é um objeto para a ética. Trad. Oswaldo Giacoia Jr. Revista Internacional de Filosofia e práticas Psicoterápicas. São Paulo: Educ. v. 1, n. 2, 1999, p. 407-422.

Press, 1996.

Mortality and Morality: A search for good after Auschwitz. Evanston, Northwestern University

The Scientific and Technological Revolutions. Philosophy Today 15, Summer 1971, p. 76-101.

247.

Philosophical Reflections on Experimenting with human subjects. Daedalus, 98, n² 2, 1968, p. 219-

Ethics and Biogenetic Art. Social Research. 52, 1985, p. 491-504. (Ethics and Biogenetic Art. Social

Research $71 \mathrm{n}^{\circ}$ 3, Fall 2004, p. 569-582).

Poder o impotencia de la subjetividad. Trad. e Introdução De Illana Giner Comín. Barcelona: Paidós;

I. C. E. de la Universidad Autónoma de Barcelona, 2005.

Le Droit de Mourir. Trad. de Philippe Ivernel do título original «Tecchniken des todesanfschubs und das Recht in Sterben (1985)», Rivages Poche, Paris, 1996.

Évolution et liberté. Trad, de Sabine Cornille e Philippe Ivernel, do título original «Philosophische

Untersuchungen und metaphysische Vermutungen (1992)», Payot \& Rivages, Paris, 2000.

O fardo e a bênção da mortalidade. Trad. Wendell Evangelista Soares Lopes. Princípios (Natal), v.16, n.25, p. 265-281, jan./jun. 2009.

Matéria, Espírito e Criação: dados cosmológicos e conjecturas cosmogônicas. Trad. Wendell Evangelista Soares Lopes. Petrópolis: Vozes, 2010.

\section{Outras obras e artigos}

ARISTOTELES. Ética a Nicômaco. São Paulo: Nova Cultural, 1987. Vol. II. Coleção os (Pensadores).

DUPAS, Gilberto. A Busca de uma Ética para os Novos Tempos. In: Ética e Poder na Sociedade da Informação: de como a autonomia das novas tecnologias obriga a rever o mito do progresso. ( $2^{\mathrm{a}}$ ed. rev. e amp.). São Paulo: Editora UNESP, 2001, p. 69-89.

FROGNEUX, Nathalie. Hans Jonas ou la vie dans le monde. Préface de Jean Greisch, De Boeck Université, 2001.

GIACOIA, Oswaldo. Hans Jonas: O Princípio Responsabilidade, Ensaio de uma ética para a civilização tecnológica, in CAD. HIST. FIL. CL, Universidade Estadual de Campinas, Série 3, Vol. 6, n 2, Jul.-Dez. 1996, p. 63-84.

GOFFI, Jean-Yves. Communauté éthique et communauté politique. HOTTOIS, G. \& PINSART, M.-G (Éds.). Aux Fondements d'une Ethique Contemporaine: H. Jonas et H. T. Engelhardt. Paris: Vrin, 1992, p. 205-222.

HOTTOIS, Gilbert. Aux Fondements d'une Éthique Contemporaine - Hans Jonas et H. T. Engelhardt, Vrin, Paris, 1993.

IGLESIAS, Juan Carlos. A Heurística do Temor na Ética da Preservação de Hans Jonas. In: SIQUEIRA, José Eduardo de; PROTA, Leonardo; ZANCANARO, Lourenço (Orgs.). Bioética: estudos e reflexões. Londrina: Ed. UEL, 2000, p. 71-99.

LOPES, Wendel Evangelista Soares. A necessidade de um fundamento metafísico para a ética. In: Filosofia Unisinos, 10(3): set/dez 2009, p. 178-190.

NEDEL, José. Ética da Responsabilidade segundo Hans Jonas. In: Ética Aplicada. São Leopoldo: Unisinos. 2006, p. 143-168.

NUNES, Amauri Porto. As Implicações Éticas da Manipulação Genética em Seres Humanos Segundo o Princípio Responsabilidade de Hans Jonas. In: SIQUEIRA, José Eduardo de; PROTA, Leonardo; ZANCARANO, Lourenço (Orgs.). Bioética: estudos e reflexões. Londrina: Ed. UEL, 2000, p. 117-134.

OLIVEIRA, Jelson Roberto de. Por que uma ética do futuro precisa de uma fundamentação metafísica. Revista de. Filosofia, Aurora, Curitiba, v. 24, n. 35, p. 387-416, jul./dez. 2012.

KANT Immanuel. Fundamentação da Metafísica dos Costumes. Trad. Paulo Quintino. Lisboa: Edições 70, 1991.

RENAUD, Michel. Os Direitos das Gerações Vindouras, in BIOÉTICA, (coord.) ARCHER, Luís, BISCAIA, Jorge e OSSWALD, Walter, Editorial Verbo, 1996, p. 150-154

RICOUER, Paul. La Responsabilité et la Fragilité de la Vie: Ethique et Philosophie de la Biologie chez Hans Jonas, in Le MESSAGER EUROPÉEN, n ${ }^{\circ}$, Gallimard, 1991, p. 203218.

Ética e Filosofia da Biologia em Hans Jonas. In: Leituras 2: a região dos filósofos. SP: Edições Loyola, 1996, p. 229-244.

\begin{tabular}{|c|c|c|c|c|c|}
\hline intuitio & $\begin{array}{c}\text { ISSN } \\
1983-4012\end{array}$ & Porto Alegre & Vol.7 - N .2 & $\begin{array}{c}\text { Novembro } \\
2014\end{array}$ & p. 146-160 \\
\hline
\end{tabular}


A teoria da responsabilidade de Hans Jonas como resposta ética aos problemas levantados pela técnica moderna

ROSALES RODRÍGUEZ, Amán. Hans Jonas y el determinismo tecnológico, Revista de Filosofía de la Universidad de Costa Rica, XXXVII (93), 1999, p. 313-320.

. Ciencia es poder: interpretaciones criticas del legado baconiano (1 parte). Revista de Filosofia de la Universidad de Costa Rica. 37(92), 1999, p. 261-271.

SÈVE, Bernard. 1990. Hans Jonas et l'Éthique de la Responsabilité. Esprit, 10(165):72-88.

. La peur comme procedée heuristique et comme instrument de persuasion. HOTTOIS, G. \& PINSART, M.-G (Éds.). Aux Fondements d'une Ethique Contemporaine: H. Jonas et H. T. Engelhardt. Paris: Vrin, 1992, p. $107-125$.

SIQUEIRA, José Eduardo de. Hans Jonas e a Ética da Responsabilidade. O Mundo da Saúde, São Paulo, ano 23, v. 23, n. 5, set./out. 1999.

. Ética e Tecnociência: uma abordagem segundo o princípio de responsabilidade de Hans Jonas. In: SIQUEIRA, José Eduardo de (Org.). Ética, Ciência e Responsabilidade. São Paulo: Centro Universitário São Camilo: Loyola, 2005, p.101-200.

ZANCANARO, Lourenço. O Conceito de Responsabilidade em Hans Jonas. Tese Doutoral. Campinas, 1998. . A Ética da Responsabilidade de Hans Jonas. In: BARCHIFONTAINE, Christian de Paul \& PESSINI, Leo (Orgs.) Bioética: alguns desafios. SP: Ed. Loyola, 2001, p. 137-259.

Recebido em: 02/09/2014

Aprovado para publicação em: 24/09/2014

\begin{tabular}{|c|c|l|l|l|l|}
\hline intuitio & $\begin{array}{c}\text { ISSN } \\
1983-4012\end{array}$ & Porto Alegre & Vol.7- $\mathrm{N}^{\mathrm{o} .2}$ & $\begin{array}{c}\text { Novembro } \\
2014\end{array}$ & p. 146-160 \\
\hline
\end{tabular}

